\title{
Ulcerative colitis and Crohn's disease in an unselected population of monozygotic and dizygotic twins. A study of heritability and the influence of smoking
}

\author{
C TYSK, E LINDBERG, G JÄRNEROT, AND B FLODÉRUS-MYRHED \\ From the Department of Medicine, Division of Gastroenterology, Örebro Medical Center Hospital, Örebro, \\ and Department of Hygiene, Karolinska Institute, Stockholm, Sweden
}

SUMMARY By running the Swedish twin registry containing about 25000 pairs of twins of the same sex together with the central national diagnosis register of hospital inpatients, 80 twin pairs suffering from inflammatory bowel disease were found. In the ulcerative colitis group one of 16 monozygotic pairs was concordant for the disease, but all the other 20 pairs (dizygotic or unknown zygosity) were discordant. In the Crohn's disease group eight of 18 monozygotic pairs and one of 26 dizygotic pairs were concordant. The proband concordance rate among monozygotic twins was $6 \cdot 3 \%$ for ulcerative colitis and $\mathbf{5 8 \cdot 3 \%}$ for Crohn's disease. The calculated heritability of liability based on monozygotic pairs was 0.53 and 1.0 respectively. Thus heredity as an aetiological factor is stronger in Crohn's disease than in ulcerative colitis. Monozygotic twins with Crohn's disease were more likely to be smokers than monozygotic twins with ulcerative colitis. Smoking did not explain the discordance of twin pairs with either ulcerative colitis, or Crohn's disease. The combination of identical heredity and similar smoking habit is not sufficient to cause disease.

There is an increased prevalence of inflammatory bowel disease (IBD) among relatives of patients with ulcerative colitis (UC) and Crohn's disease (CD) and the two diseases can appear in the same family. Although genetic factors are important uncertainty exists if they are equally significant in UC and in CD. For instance, Monsén et al $l^{1}$ found a 15 times higher prevalence of UC in first degree relatives than in the general population of Stockholm. Similarly Mayberry et al $^{2}$ in Cardiff found a 13 times greater prevalence of $\mathrm{CD}$ in first degree relatives in comparison with non-relatives. This might indicate that genetic factors carry the same weight in UC as in CD. On the other hand McConnell, in a survey of the literature, found 11 pairs of monozygotic (MZ) twins with UC of which five were concordant ${ }^{3}$ while Weterman and $\mathrm{Pena}^{4}$ reported 20 pairs of monozygotic twins with $\mathrm{CD}, 17$ concordant, and only three

Address for correspondence: Gunnar Järnerot, MD, Department of Medicine. Division of Gastroenterology. Örebro Medical Center Hospital, S-701 85 Örebro, Sweden.

Received for publication 22 January 1988. pairs discordant for the disease. These two reports indicate that genetic factors are significant in both diseases, but more so for CD than for UC. Such reports might, however, be biased, as concordant pairs are more likely than discordant pairs to become known to the physician and also for their circumstances to be published. To our knowledge no previous study of unselected twins with IBD has been reported.

\section{Methods}

SUBJECTS

The Swedish twin registry at the Department of Environmental Hygiene, Karolinska Institute, Stockholm, contains about 25000 pairs of monozygotic or dizygotic twins of the same sex born between 1886-1958. Since 1964 a central diagnosis register of hospital inpatients has been organised at the National Board of Health and Welfare, Stockholm. This has covered all inpatients in Sweden since 1984 although initially it only covered certain areas of Sweden. In order to find an unbiased population of 
twins suffering from $\mathrm{UC}$ or $\mathrm{CD}$ these two registers were matched.

The study was approved by the National Swedish Board of Health and Welfare and the Swedish Data Inspection Board.

All hospital inpatients who had been cared for under the diagnosis of ileitis terminalis, enteritis regionalis, colitis chronica ulcerosa, proctitis ulcerosa, enterocolitis ulcerosa, enterocolitis alia definita or enterocolitis NUD according to the WHO diagnosis register ${ }^{5}$ were run against the twin registry. One hundred and five pairs of twins with one or other of these diagnoses were found. In 50 pairs UC could be a possible diagnosis in one or both twins and in the other 55 pairs $C D$.

The medical notes from the hospitals where the patients had been treated were scrutinised. The diagnosis of UC was based on the clinical history, sigmoidoscopy, barium enema and/or colonoscopy together with the histology reports. The diagnosis of $\mathrm{CD}$ was made from the clinical history, radiology of the small and large bowel, together with pathology reports on endoscopic biopsies or surgical specimens. Of the 50 pairs of twins suspected to suffer from UC 14 pairs were excluded for the following reasons: infectious disease $(n=8)$, antibiotic associated diarrhoea $(n=3)$, missing medical notes $(n=1)$. In two pairs the diagnosis in the affected twin had been subsequently changed to $C D$. These two pairs were added to the $C D$ group. Of the 55 pairs suspected to suffer from $C D, 13$ pairs were excluded: Infectious disease $(n=6)$, systemic lupus $(n=1)$, ischaemic bowel disease $(n=1)$, and abdominal complaints without any definite diagnosis $(n=5)$.

Thirty six pairs remained where one or both twins had UC. Of these, 16 pairs were monozygotic, 17 pairs dizygotic while the zygosity was unknown in three pairs. Of the 44 twin pairs with CD 18 pairs were monozygotic and 26 dizygotic. The zygosity classification of the twin registry was used. The method relies on questions on childhood resemblance and has proved to be very accurate. According to Cederlöf $e t a l^{6}$ a correct determination is obtained in $99 \%$ of monozygotic and $91 \%$ of dizygotic twins in comparison with serological classification. All these 80 twin pairs have been interviewed by telephone $(n=148)$ or by a postal questionnaire $(n=7)$ except for five dead individuals about whom sufficient information could be given by the surviving twin.

The occurrence of any gastrointestinal complaint was thoroughly discussed at interview of all twins in order not to miss a mild non-hospitalised case of inflammatory bowel disease. Other questions covered smoking habits, use of the contraceptive pill and major psychological trauma preceding the disease. If any of the twins earlier considered to be healthy had sought medical advice for symptoms suspected to be caused by IBD, their medical notes were also scrutinised.

Concordance rates can be calculated in two ways: (1) pair concordance, which just shows the proportion of concordant twins; (2) proband concordance, which also takes into account how the concordance was discovered, either independently as index cases $\left(C_{2}\right)$ or secondarily to the interview $\left(C_{1}\right)$. The proband concordance rate is calculated according to the formula

$$
\frac{2 C_{2}+C_{1}}{2 C_{2}+C_{1}+D}
$$

where $\mathrm{D}$ is the number of discordant pairs.

For a multifactorial disease, it can be assumed that each individual has a specific probability of being affected which is normally distributed in the population and that the disease manifests when the probability or liability exceeds the threshold level." The heritability of liability to the disease ( $r$ ) may be estimated by comparing family with general population rates (prevalence)." "I" The interpretation of the $r$ value depends on the type of relatives studied. For monozygotic twins the r-value reflects the expression of shared genes and similar environment. For dizygotic twins $r$ reflects the similarity due to shared environment and that half of the genes are in common. If the disease is independent of environment factors, the r-value of monozygotic twins or twice the r-value of dizygotic twins estimates the heritability of liability. If not, the influence of shared environmental factors may be corrected for by taking twice the difference between the $\mathrm{r}_{\mathrm{MZ}}$ and the $\mathrm{r}_{\mathrm{D}} \mathrm{z}$. This estimate reflects the proportion of variance of normally distributed disease liability which is genetic, and it may range $0-1$.

We used estimated prevalences for IBD calculated from Stockholm county" and Copenhagen." Because both estimates were very similar only the Stockholm prevalence was used.

\section{Results}

\section{ULCERATIVE COLITIS}

The mean age at the diagnosis in the twins with UC was $29 \cdot 8$ years. The male:female ratio was $1 \cdot 4: 1$. All 36 twin pairs were discordant for UC with the exception of one monozygotic pair. Disease extent is shown in Table 1. Although monozygotic twins had less extensive UC than dizygotic twins the small numbers do not allow a meaningful analysis of extent. The only concordant pair in the whole UC group was two monozygotic brothers with distal UC diagnosed at the age of 27 and 35 respectively. Neither of whom had been operated on or had had 
Table 1 Extent of the ulcerative colitis at the time of diagnosis in the individual twins

\begin{tabular}{llll}
\hline & Distal $^{*}$ & Extensive $^{+}$ & Totalł \\
\hline Monozygotic twins & 11 & & 6 \\
Dizygotic twins & 5 & 3 & 9 \\
Unknown zygosity & & & 3 \\
\hline
\end{tabular}

${ }^{*}$ Distal UC - inflammation not extending beyond the splenic flexure: textensive UC - inflammation beyond the splenic flexure but not involving the whole colon; $\$$ total - whole colon inflamed.

Table 2 Proband concordance rates and estimates of heritability of liability for ulcerative colitis (UC) and Crohn's disease (CD)

\begin{tabular}{|c|c|c|c|c|c|}
\hline \multirow[b]{2}{*}{$\begin{array}{l}\text { Prevalence } \\
\text { per } 10^{5}\end{array}$} & \multicolumn{2}{|c|}{ Monozygotictwins } & \multicolumn{2}{|c|}{ Dizygotic twins } & \multirow[b]{2}{*}{$\begin{array}{l}2\left(r_{m:-}-\right. \\
\left.r_{d:}\right)^{\neq}+\end{array}$} \\
\hline & $\begin{array}{l}\text { Prob } \\
\text { conc } \\
(\%)\end{array}$ & $r^{+}$ & $\begin{array}{l}\text { Prob } \\
\text { conc } \\
(\%)\end{array}$ & $r^{t}$ & \\
\hline UC 78 & $6 \cdot 3$ & $\begin{array}{l}0.53 \\
(0.24-0.82) \$\end{array}$ & 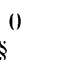 & - & - \\
\hline CD 54 & $58 \cdot 3$ & $\begin{array}{l}1 \cdot() \\
(0 \cdot 80-1 \cdot()) \S\end{array}$ & 3.9 & $\begin{array}{l}(0.47 \\
(0.20-(0.73)\end{array}$ & $\begin{array}{c}1 \cdot 0 \\
\S(0 \cdot 34-1 \cdot(0) \S\end{array}$ \\
\hline
\end{tabular}

*proband concordance: the ritability of liability; $\ddagger$ corrected $r$-value for common familial environmental factors; $\$ 95 \%$ confidence interval.

Table 3 Smoking pattern in discordant monozygotic twin pairs with ulcerative colitis at the time of diagnosis

\begin{tabular}{lllll}
\hline & & \multicolumn{2}{l}{ Diseased twin } \\
\cline { 3 - 4 } & & $\begin{array}{l}\text { Never } \\
\text { smoker }\end{array}$ & $\begin{array}{l}\text { Former } \\
\text { smoker }\end{array}$ & Simoker \\
\hline Healthy & $\begin{array}{l}\text { Never } \\
\text { smoker }\end{array}$ & 9 & & 1 \\
twin & $\begin{array}{l}\text { Former } \\
\text { smoker }\end{array}$ & & 1 & \\
& Smoker & 1 & 1 & 2 \\
\hline
\end{tabular}

any complications and neither had ever smoked. As the concordance was discovered by the interview the proband concordance is $6.3 \%$. The prevalence of UC in Stockholm has been found to be $78 / 10^{s}$ inhabitants (Hellers, personal communication). The heritability coefficient in monozygotic twins was 0.53 with a $95 \%$ confidence interval of $0 \cdot 24-0 \cdot 82$ (Table 2 ).

All twins with UC had been brought up together. No evaluable data emerged concerning psychological trauma and the use of the contraceptive pill. Firm data were obtained regarding the smoking pattern at the time of diagnosis. Table 3 shows these findings in the discordant monozygotic twins. All these 15 discordant pairs had a similar smoking pattern at the
Table 4 Dataregarding concordant monozygotic and concordant dizygotic twin pairs with Crohn's disease

\begin{tabular}{|c|c|c|c|c|c|c|c|c|c|}
\hline Pair no & 1 & 2 & 3 & 4 & 5 & 6 & 7 & 8 & 9 \\
\hline Zygosity* & $\mathrm{MZ}$ & $\mathrm{MZ}$ & $\mathrm{MZ}$ & $\mathrm{MZ}$ & $\mathrm{MZ}$ & $\mathrm{MZ}$ & $\mathrm{MZ}$ & $\mathrm{MZ}$ & $\mathrm{DZ}$ \\
\hline $\operatorname{Sex}$ & M & $\mathrm{M}$ & $\mathrm{F}$ & $\mathrm{F}$ & M & $\mathrm{F}$ & M & $\mathrm{F}$ & $\mathrm{F}$ \\
\hline Age at diagnosis & $57 / 5$ & $7.35 / 4$ & $521 / 2$. & $327 / 2$ & $626 / 27$ & $722 / 1$ & $723 / 2$ & $329 / 1$ & $4.38 / 31$ \\
\hline Extent & $1 / 1$ & $1 / 3$ & $1 / 1$ & $1 / 3$ & $3 / 2$ & $1 / 1$ & $1 / 1$ & $3 / 3$ & $3 / 3$ \\
\hline $\begin{array}{l}\text { Extraintestinal } \\
\text { complications }\end{array}$ & $+1+$ & $-1-$ & $-1+$ & $-1-$ & $-1-$ & $-1-$ & $-1-$ & $-1+$ & $+1-$ \\
\hline $\begin{array}{l}\text { Intestinal } \\
\text { complications }\end{array}$ & $\varliminf^{-1+}$ & $+1-$ & $+1-$ & $+1-$ & $+1-$ & $+1+$ & $-1-$ & $+1-$ & $-1+$ \\
\hline $\begin{array}{l}\text { Smoking } \\
\text { pattern } \|\end{array}$ & $+/ 0$ & $\mathrm{ex} /$ & $\mathrm{ex} /+$ & -1 & $+1 .+$ & $+1+$ & +1 & $\mathrm{ex}$ & -1 \\
\hline
\end{tabular}

${ }^{*} \mathrm{MZ}=$ monozygotic. $\mathrm{DZ}=$ dizygotic; $t$ extent: $1=$ small intestine, $2=$ large bowel. $3=$ combined $;$ ext raintestinal complications (erythema nodosum. iritis, arthritis, sacroileitis, vasculitis): Sintestinal complications (fistula, abscesses, fissures): $\|+=$ smoker. $-=$ never smoker. $\mathrm{ex}=$ former smoker at the time of diagnosis of CD

Table 5 Smoking pattern in discordant monozygotic twin pairs with Crohns disease at the time of diagnosis

\begin{tabular}{lllll}
\hline & & \multicolumn{2}{l}{ Diseased twin } \\
\cline { 3 - 4 } & & $\begin{array}{l}\text { Never } \\
\text { smoker }\end{array}$ & $\begin{array}{l}\text { Former } \\
\text { smoker }\end{array}$ & Smoker \\
\hline Healthy & $\begin{array}{l}\text { Never } \\
\text { smoker }\end{array}$ & 3 & 1 & \\
twin & $\begin{array}{l}\text { Former } \\
\text { smoker }\end{array}$ & & & \\
& Smoker & 1 & 1 & 4 \\
\hline
\end{tabular}

time of diagnosis in the diseased twin, except for three pairs. During the time between the diagnosis and the survey, two of the four healthy twins who had been smokers had given up. These two twins have remained healthy during an observation period of seven and six years respectively. In the diseased twin group one subject who was an exsmoker at the time of diagnosis had started to smoke again. All other monozygotic twins had unchanged smoking pattern during this period. The mean observation time in the healthy twin was 19.4 (6-38) years after the diagnosis of UC in the twin partner.

\section{CROHN'S DISEASE}

The mean age at diagnosis of CD was $30 \cdot 3$ (14-57) years for concordant pairs and 29.5 (17-59) years for discordant. The male:female ratio was $0 \cdot 8: 1$. The localisation of the inflammation was similar to other larger epidemiological studies." Of 18 monozygotic twin pairs eight were concordant for the disease; six pairs were found as index cases and another two pairs by the interview. This gives a proband concordance of $58 \cdot 3 \%$. Only one of 26 dizygotic twin pairs was 
concordant. The proband concordance of $3.9 \%$ in dizygotic twins was significantly lower than for monozygotic twins. The prevalence of CD in Stockholm has been found to be $54 / 10^{5}$ inhabitants." The heritability was 1.0 with a $95 \%$ confidence interval of $0 \cdot 80-1.0$ and for dizygotic twins 0.47 with a $95 \%$ confidence interval of $0 \cdot 20-0 \cdot 73$ (Table 2 ). The $r$ value corrected for shared environments is still 1.0 although the $95 \%$ confidence interval becomes wide $(0 \cdot 34-1 \cdot 0)$. The monozygotic r-values for UC and CD differ significantly $(\mathrm{p}<0 \cdot 005)$.

All twins with $C D$ had been brought up together. As with the UC twins no evaluable risk data regarding psychologic trauma or the use of the contraceptive pill could be gained. Good information on the smoking pattern at the time of diagnosis, however, could be obtained. As shown in Table 4 the smoking habits at diagnosis of concordant monozygotic twins were very similar. Table 5 shows the smoking pattern of the discordant group of monozygotic twins at diagnosis. Eight of the 10 pairs had identical or similar smoking pattern. During the time between the diagnosis and survey, both twins in one pair had stopped smoking and in another pair both twins who had never been smokers had started to smoke. The healthy twins in these two pairs have been observed for five and two years respectively without acquiring $\mathrm{CD}$. In a third pair the diseased twin had continued smoking while the healthy twin had given up smoking for one year and had remained well. In the remaining seven discordant monozygotic twin pairs, the smoking pattern was unchanged. The difference between the UC and $\mathrm{CD}$ groups regarding nonsmoking (never-smoking, former smoking) at the time of diagnosis is statistically significant $\left(\chi^{2}=6 \cdot 5\right.$, $\mathrm{p}<0 \cdot(05)$.

As shown in Table 4, most of the concordant monozygotic twins had a similar distribution of disease. In five of the eight concordant monozygotic pairs the disease was diagnosed within a period of two years. In the remaining three pairs the interval was $5-15$ years. The mean observation time of the healthy twin in the group of discordant monozygotic twins was 12.9 (5-29) years after the diagnosis of $C D$ in the diseased twin. The occurrence of both extraintestinal and intestinal complications did not seem to be genetically determined as no consistent pattern could be detected in concordant pairs (Table 4). In no twin pairs with UC or CD did the two diseases occur intermingled.

\section{Discussion}

Both UC and CD are multifactorial disorders with significant genetic influence. In this respect, twin studies are of great value. Classical twin studies are based on a comparison between monozygotic and dizygotic twins. A significantly higher degree of concordance in the monozygotic than in the dizygotic twins suggests a genetic influence if the environment is shared to the same extent. Earlier recorded twin surveys of UC and CD have been based on summaries of case reports with a large risk of selection bias. We are well aware that our selection method excludes patients who have been treated only as outpatients. This should to a higher extent concern UC than CD. Without corrections for deaths the total prevalence of UC in the twin registry can roughly be estimated to $74 / 10^{5}$ and for CD $106 / 10^{5}$. These figures differ from those found in Stockholm but are well within the limits reported from the Western world in general. ${ }^{1:}$ Thus we do not believe that our general findings and conclusions are affected in any major way by our selection method.

\section{ULCERATIVE COLITIS}

A survey of the literature has revealed 16 pairs of monozygotic twins with $\mathrm{UC}^{1+25}$ excluding that of Lyons and Postlethwait ${ }^{2 h}$ which we do not find absolutely convincing for UC. We have added another three pairs well known to us and not found as a result of this study, either because they had not been hospitalised or were born after 1958. Of these 19 monozygotic pairs, nine are concordant compared with one of the 16 pairs in our study $\left(\chi^{2}=7 \cdot 3\right.$, $\mathrm{p}<0 \cdot 01)$. One of seven reported pairs of dizygotic twins ${ }^{127-24}$ was concordant while we found no concordant case in 17 dizygotic pairs. In three reported, discordant twin pairs $^{31-32}$ the zygosity was not mentioned.

It could be argued that some of the healthy twins in our study could still contract UC. The mean observation time of 19.4 years, however, should be sufficient in this respect. These findings indicate that evaluations based on earlier twin reports have probably overestimated the importance of genetic factors in UC.

The heritability estimate found in our study of 0.53 in monozygotic twins is still fairly high, although the $95 \%$ confidence interval is wide $(0 \cdot 24-0 \cdot 82)$. This can be compared with some other diseases considered to be partly genetically determined such as diabetes $(r=0.77)$, duodenal ulcer $(r=0.46)$, schizophrenia $(r=0.68)$, hypertension $(r=0.57)$, and bronchial asthma $(\mathrm{r}=0 \cdot 29) .{ }^{33}$ Our results of heritability may be influenced by shared familial environmental factors, the effect of which is impossible to assess as there were no concordances among the dizygotic twins. Thus genetic factors cannot be disregarded in the aetiology of UC but they are probably weak.

Samuelsson showed that non-smoking was a feature in UC but he did not analyse the smoking 
pattern at the time of diagnosis. ${ }^{34}$ Our recent study of this matter showed that cigarette smoking has a protective effect in a dose dependent way and that the risk of UC increases in former smokers and especially in those who have smoked heavily. ${ }^{35}$ Also in this twin study non-smoking was a characteristic feature of UC but not of CD. This population of monozygotic twins with UC showed similar smoking patterns in the concordant and in the discordant pairs. After the time of diagnosis two healthy monozygotic twins had given up smoking during a mean observation time of 6.5 years without contracting UC. Apparently not even the combination of identical heredity and smoking pattern is enough to cause UC and additional environmental factors are needed.

\section{CROHNS DISEASE}

The literature revealed 27 pairs of monozygotic twins including one pair of monozygotic triplets with $C D$, of which 24 pairs were concordant. ${ }^{+1136-5 x}$ Two of eight reported dizygotic twins were concordant ${ }^{4} 3659$ (6) and we can add one more discordant dizygotic pair known to us. In the literature there are six further reports ${ }^{61-65}$ where zygosity is not mentioned and of these four are concordant. Of the three monozygotic twin pairs with IBD reported by Carlisle and Hersh" the nature of the disease can be determined with absolute certainty in only one pair from the abstract. This pair with $\mathrm{CD}$ has been included above. The reports by Ehrenpreis et $\mathrm{l}^{+4}$ and Lagercrantz $\mathrm{z}^{+x}$ concern the same twin pair (Lagercrantz, personal communication). All twins which have been reported only as personal communications have been excluded, which explains why we present a smaller number of twins than in the survey by Purrmann et $a l .{ }^{36}$ Some of the healthy twins in our study might still contract $C D$ but the long mean observation time makes it unlikely that the concordance rate will reach the same level as in the literature survey. The CD heritability of 1.0 is extremely high and suggests a much larger genetic influence than in UC. The $r$ value of 1.0 corrected for common familial environmental factors also suggests a strong genetic influence. Our numbers of patients are still relatively small, however, with resulting wide confidence limits of the point estimates.

One possible aetiological factor is cigarette smoking, which is much more common in patients than in the general population. ${ }^{3566}$ Here the smoking pattern in monozygotic twins was very similar in concordant and discordant pairs. From the time of diagnosis to the time of survey, three healthy monozygotic twins had changed their smoking pattern without developing $\mathrm{CD}$ during a mean observation period of 2.7 years. Thus identical heredity plus similar smoking habits are not sufficient in themselves to cause $C D$ but additional factors are needed.

The majority of the concordant twin siblings developed $\mathrm{CD}$ within a period of two years, and the extent of the disease was very similar.

This study was financially supported by the Swedish ILCO and the Örebro County Research committee. Curt Tysk and Eva Lindberg were awarded the Nanna Svartz grant to undertake this study and this is gratefully acknowledged.

\section{References}

1 Monsén U, Broström O, Nordenvall B, Sörstad J, Hellers G. Prevalence of inflammatory bowel disease among relatives to patients with ulcerative colitis. Scand J Gastroenterol 1987; 22: 214-8.

2 Mayberry JF, Rhodes J, Newcombe RG. Familial prevalence of inflammatory bowel disease in relatives of patients with Crohns disease. Br Med J 1980; i: 84.

3 McConnell RB. Ulcerative colitis - genetic features. Scand J Gastroenterol [Suppl 88] 1983; 18: 14-6.

4 Weterman IT, Pena AS. Familial incidence of Crohns disease in the Netherlands and a review of the literature. Gastroenterology 1984; 86: 449-52.

5 Socialstyrelsen: Klassifikation av sjukdomar. Stockholm, 1982.

6 Cederlöf R, Friberg L, Jonsson E, Kaij L. Studies on similarity diagnosis in twins with the aid of mailed questionnaires. Acta Genet 1961; 11: 338-62.

7 Allen G, Hrubec Z. Twin concordance. A more general model. Acta Genet Med Gemellol (Roma) 1979; 28: 3-13.

8 Falconer DS. The inheritance of liability to certain diseases, estimated from the incidence among relatives. Ann Hum Genet 1965; 29: 51-76.

9 Smith C. Heritability of liability and concordance in monozygotic twins. Ann Hum Genet 1970; 34: 85-91.

10 Smith C. Concordance in twins: Methods and interpretation. Am J Hum Genet 1974; 26: 454-66.

11 Hellers G. Crohns disease in Stockholm County 1955 1974. Acta Chir Scand [Suppl] 1979: 490.

12 Binder V, Both J, Hansen PK, Hendriksen C, Kreiner $\mathrm{S}$, Torp-Pedersen $\mathrm{K}$. Incidence and prevalence of ulcerative colitis and Crohns disease in the county of Copenhagen 1962-1978. Gastroenterology 1982; 83: 563-8.

13 Calkins BM, Mendeloff AI. Epidemiology of inflammatory bowel disease. Epidemiol Rev 1986; 8: 60-91.

- 14 Webb LR. The occurrence of chronic ulcerative colitis in twin males. Gastroenterology 1950; 15: 523-4.

15 Sleight DR, Galpin JE, Condon RE. Ulcerative colitis in female monozygotic twins and a female sibling. Gastroenterology 1971; 61: 507-12.

16 Sanford GE. Genetic implications in ulcerative colitis. Am Surg 1971; 37: 512-7.

17 Powell JR. Concordance of arthritis and iritis in identical twins with ulcerative colitis. J Natl Med Assoc 1974; 66: $305-7$.

18 Fausa O, Fretheim B, Flatmark A, Froland S, Gjone E. Ulcerative colitis in monozygotic twins. Scand $J$ Gastroenterol [Suppl 16] 1972; 7: 38. 
19 Mayberry JF, Dew MJ, Morris JS. Monozygotic twins with ulcerative colitis. Postgrad Med J 1982; 58: 112-4.

20 Quigley EMM, Larusso NF, Ludwig J, MacSween RNM, Birnie GG, Watkinson G. Familial occurrence of primary sclerosing cholangitis and ulcerative colitis. Gastroenterology 1983; 85: 1160-5.

21 Quazi QH, Piken E, Fierst S. Discordant occurrence of ulcerative colitis in identical twins. Gastroenterology 1973; 65: 134-6.

22 Kemler BJ, Glass D, Alpert E. HLA studies of families with multiple cases of inflammatory bowel disease (IBD). Gastroenterology 1980; 78: 1194.

23 Gregg JA, Baggenstoss AH. Discordance for ulcerative colitis in identical twins concordant for cholestatic liver disease. Am J Dig Dis 1970; 15: 667-71.

24 Marie J, Ledoux-Lebard G. Rectocolitis hemorragiques chez un enfant. Caractère familial de l'affection. Arch Mal App Dig 1942; 31: 71-86.

25 Thayer WR, Spiro HM. Protein abnormalities in ulcerative colitis patients and their families. Gastroenterology 1963; 44: 444-7.

26 Lyons CK, Postlethwait RW. Chronic ulcerative colitis in twins. Gastroenterology 1948; 10: 545-50.

27 Bacon HE. Ulcerative colitis. Philadelphia: JB Lippincott Co, 1958: 3.

28 Binder V, Weeke E, Olsen JH, Anthonisen P, Riis P. A genetic study of ulcerative colitis. Scand J Gastroenterol 1966; 1: 49-56.

29 Kirsner JB. Genetic aspects of inflammatory bowel disease. Clin Gastroenterol 1973; 2: 557-75.

30 Barker WF. Familial history of patients with ulcerative colitis. Am J Surg 1962; 103: 25-6.

31 Finch SM, Hess JH. Ulcerative colitis in children. $A m \mathrm{~J}$ Psychiatry 1962; 9: 819-26.

32 Lagercrantz R. In: Ulcerös kolit Örebro: (Pharmacia), 1974: 14-8.

33 Kendler KS. Overview: A current perspective on twin studies of schizophrenia. Am J Psychiatry 1983; 140: 1413-25.

34 Samuelsson SM. Ulcerös kolit och proktit. Uppsala: Department of Social Medicine. University of Uppsala: Thesis, 1976: 128.

35 Lindberg E, Tysk C, Andersson K, Järnerot G. Smoking and inflammatory bowel disease. A casecontrol study. Gut 1988; 29: 352-7.

36 Purrmann J, Bertrams J, Borchard F, et al. Monozygotic triplets with Crohns disease of the colon. Gastroenterology 1986; 91: 1553-9.

37 Edwards HC. Crohns disease. In: Edwards HC, ed. Recent advances in surgery. London: Churchill, 1954: 170-1.

38 Anfanger H. Regional ileitis in children. J Mount Sinai Hosp 1955; 22: 187-91.

39 Freysz H, Haemmerli A, Kartagener M. Ileitis regionalis bei einem weiblichen Zwillingspaar. Gastroenterologia 1958; 89: 75-82.

40 Niederle MB. Iléite régionale chez des jumelles univitellines. Arch Mal App Dig 1961; 50: 1245-6.

41 Crismer R, Dréze Ch, Dodinval P. Iléite de Crohn chez des jumeaux univitellins. Acta Genet Med Gemellol (Roma) 1963; 12: 358-68.

42 Sherlock P, Bell BM, Steinberg H, Almy TP. Familial occurrence of regional enteritis and ulcerative colitis. Gastroenterology 1963; 45: 413-20.

43 Hislop IG, Grant AK. Genetic tendency in Crohns disease. Gut 1969; 10: 994-5.

44 Milton-Thompson GJ, Lennard-Jones JE. A pair of probable monozygotic twins with colonic Crohns disease. Proc R Soc Med 1971; 64: 570.

45 Berg NO, Dencker H. Crohns disease in monozygotic twins. Acta Chir Scand 1972; 138: 633-5.

46 Goldstein F, Abraham AA, Abramson J, Thornton JJ. Ileojejunitis in a pair of identical twins. Gastroenterology 1976; 71: 670-4.

47 Morichau-Beauchant M, Matuchansky C, Dofing JL, Yver L, Morichau-Beauchant J. Entérite régionale chez des jumeaux homozygotes. Gastroenterol Clin Biol 1977; 1: 783-8.

48 Lagercrantz R. Crohns disease in children and adolescents. In: Weterman I, Pena AS, Booth C, eds. The management of Crohns disease. Amsterdam: Excerpta Medica, 1976: 37-40.

49 Ehrenpreis Th, Gierup J, Lagercrantz R. Chronic regional enterocolitis ( $\mathrm{Mb}$ Crohn) in children and adolescents. Acta Paediatr Scand 1971; 60: 209-15.

50) Klein GL, Ament ME, Sparkes RS. Monozygotic twins with Crohns disease. A case report. Gastroenterology 1980; 79: 931-3.

51 Carlisle WR, Hersh T. Clinical manifestations of familial inflammatory bowel disease (IBD). Gastroenterology 1978; 74: 1017.

52 Stöcker W, Otte M, Ulrich S, Normann D, Stöcker K, Jantschek G. Autoantikörper gegen exokrines Pankreas und gegen Intestinale Becherzellen in der Diagnostik des morbus Crohn und der Colitis ulcerosa. Dtsch Med Wochenschr 1984; 109: 1963-9.

53 Hajek-Rosenmayr A, Lochs H, Kiss A, Sedlmayer A, Gangl A, Mayr WR. Vererbung von HLA-merkmalen und familiärer morbus Crohn in zehn Familien. $Z$ Gastroenterol 1984; 9: 542.

54 Oehlert W. Die Pathologie des morbus Crohn. Therapiewoche 1979; 29: 121-32.

55 Gonzales BC, Miar PA, Baniela N, Diego JIF, Rivela M, Gomez JL. Enfermedad de Crohn en gemelas univitelinas. An Esp Pediatr 1983; 19: 309-14.

56 Sirlin SM, Benkov KJ, Kazlow P, Dolgin S, Dische MR. LeLeiko NS. Identical twins concordant for Crohns disease. J Clin Gastroenterol 1986; 8: 290-4.

57 Bitter J. Crohns disease in monozygotic twins. Cs $R$ Gastroenterol Vyz 1977; 31: 199-202.

58 Saez LR, Alvarez RP, Lombrana JLS, Orduna A, Valerdiz S, Castrillo JMA. Enfermedad de Crohn en gemelos monocigóticos: descripción de un neuvo caso y revisión de la literatura. Rev Esp Enferm Ap Digest 1985; 68: $525-30$.

59 Strik WO, Strik W. Familiäres Auftreten der Enteritis regionalis Crohn bei zweieiigen Zwillingen und zwei weiteren Geschwistern. Munch Med Wochenschr 1972; 43: $1852-6$.

60) Atwell JD, Duthie HL, Goligher JC. The outcome of Crohns disease. Br J Surg 1965; 52: 966-72.

61 Dassel PM. A familial pattern in inflammatory disease of the bowel (Crohns disease and ulcerative colitis). Dis Colon Rectum 1977; 20: 669-71. 
62 Sheehan RG, Necheles TF, Lindeman RJ, Meyer HJ, Patterson JF. Regional enteritis and granulomatous colitis associated with erythrocyte glucose-6-phosphate dehydrogenase deficiency. $N$ Engl J Med 1967; 227: 1124-6.

63 Korelitz BI. From Crohn to Crohns disease. 1979. An epidemiologic study in New York City. Mt Siani J Med 1979; 46: 533-40.
64 Rueff F. Grabiger A. Bohmert H, Hamperl D. Hoffman K. Zur Klinik des morbus Crohn. Munch Med Wochenschr 1975; 117: 1009-16.

65 Richter G, Martens W. Zur Ätiologie der Enteritis regionalis. Therapiewoche 1977; 27: 3349-55.

66 Somerville KW, Logan RFA. Edmond M, Langman MJS. Smoking and Crohns disease. Br Med J 1984; 289: 954-6. 